I give four of Professor Shuster's conclusions.

"1. The principal part of the diurnal variation [of the needle] is due to causes outside the earth's surface, and probably to electric currents in our atmosphere.

" 3 . As regards the currents induced by the diurnal variation, the earth does not behave as a uniformly conducting sphere, but the upper layers must conduct less than the inner layers.

"4. The horizontal movements in the atmosphere which must accompany a tidal action of the sun or moon, or any periodic variation of the barometer such as is actually observed, would produce electric currents in the atmosphere, having magnetic effects similar in character to the observed variation.

" 5 . If the variation is actually produced by the suggested cause, the atmosphere must be in that sensitive state in which, according to the author's experiments, there is no lower limit to the electromotive force producing a current."

Meteorologists are now becoming somewhat accustomed to seeing suggestions from generally recognized authorities, showing the possibility of some kind of electric action taking place in the atmosphere, though I do not claim that this view is accepted as yet in any except an extremely limited sense as an explanation of atmospheric phenomena. I do not fully understand some of Professor Shuster's views. The expression "convection currents which flow" does not convey a definite meaning. Just how electric currents are to be induced in the upper air strata by a wave of heat is also not entirely plain. The expression "the horizontal motion which must accompany the change in pressure," as applied to the diurnal range of pressure, I think, simply means the horizontal propagation of a wave of pressure, and not any actual motion of air. I can hardly see how the convection currents of a thermal wave with the minimum point in the lower air strata at sunrise, and the maximum point about 3 P.M., can possibly induce electric currents having critical points at 10.30 A.M. and 3 P.M. It is generally accepted that the diurnal range of temperature in the free air is practically nothing at heights above five thousand feet; so that the supposed convection currents from the direct thermal effect cannot induce electric currents in the upper strata.

It seems to me there is also an objection to Dr. Hann's view, that the diurnal range of air-pressure can be due to the direct heat-action (Wärmewirkung) of the sun upon the upper limits of the atmosphere.

I have very recently discovered a method of studying the diurnal range of air-pressure and allied phenomena which seems capable of great extension, and possibly of displaying many important facts. For many years I have searched for a simple method of separating out the accidental variations of pressure, temperature, moisture, etc., in our atmosphere, produced by the progress of high and low areas, from those which are more or less constant in their action. It is quite well established that these highs and lows (called by many "anticyclones" and "cyclones") hare a common progression from west to east, especially in this country. The plan proposed is to carry back the conditions observed at any moment in the atmosphere to a point of time several hours before, say twelve hours, or especially twenty-four hours. This becomes a simple matter when we have a regular advance in a high or low; for we can place its centre at the point where it was twelve or twenty-four hours previonsly, and then at once read off the amount of change at each station for either of those intervals of time. During the month of August, 1890, I had occasion to try this method for determining the diurnal range of air-pressure from 8 A.M. to 8 P.M., and vice versa; and the results were of the highest interest. For example: on $A$ ug. 6 , at 8 P.M. there was a fall in pressure in twelve hours of from one tenth to two-tentbs of an inch from the Atlantic to the 10\%th meridian. The next morning there was almost a complete recovery over this region. On the 8 th in the morning there was a rise of from one-tenth to twotenths of an inch over the whole, and at 8 P.M. of the same day there was a fall of one tenth of an inch over half, the above region. I found the general tendency for this diurnal range in air-pressure to be the same for both highs and lows, though the fall is generally slightly greater in the low, and vice versa in the high. It should be noted that this diurnal range was often obliterated, or even carried in an opposite direction, in some parts of the country when it was impossible to centre exactly the two maps. There was a law, however, showing a marked general rise in pressure in the forenoon, and a corresponding fall in the afternoon. This may be seen to be all the more remarkable, since the observations were made at 8 A.M. and 8 P.M, 75th meridian time, and not at 10.30 A.M. and 3 P.M., which are the maximum and minimum points in the diurnal range. We see that these changes in airpressure are not due to the advance of any air-wave or of air-particles, for this would imply a velocity of over two hundred miles an hour for this region alone. The rise in pressure in the forenoon cannot be due to an inflow of air from surrounding regions, because the rise occurs over all the surrounding region. It seems impossible to consider that any direct thermal effect can do more than simply heat the air without changing its pressure. It seems to me we are driven to the hypothesis that these changes are brought about by some agency outside of the earth. Is it incredible to suppose that there is a thermo-electric action from the sun upon the atmosphere propagated like a wave one thousand miles per hour, which is the principal cause of the diurnal range of both the magnetic needle and of air-pressure, and upon which other effects may be superposed?

Washington, Oct. 18.

\section{Origin of Right or Left Handedness.}

THE question of the nature and origin of right or left handedness has given rise to much discussion in late years, the convic tion growing among investigators that it is due to some hidden difference in the structure or function of the two hemispheres of the brain. The best résumé and general discussion of the question is the learned monograph by Sir Daniel Wilson entitled "The Right Hand and Left-handedness," being a reprint from the "Transactions of the Royal Society of Canada," Section II., 1886.

In order to examine more particularly into the time at which the child begins to show signs of marked preference for either hand, I instituted a series of experiments upon my own child, extending them over the greater part of the first year. As I have no time at present to write up the results systematically, I wish simply to announce a point or two which may be of interest to students of the subject.

1. I found no trace of preference for either hand as long as there were no violent muscular exertions made (based on 2,187 systematic experiments in cases of free movement of hands near the body: i.e., right hand 585 cases, left hand 568 cases, a difference of 17 cases; both hands 1,034 cases; the difference of 17 cases being too slight to have meaning).

2. Under the same conditions the tendency to use both hands: together was about double the tendency to use either (seen from the number of cases of the use of both hands in the statistics given above), the period covered being from the child's sixth to her tenth month inclusive.

3. A distinct preference for the right hand in violent efforts in reaching became noticeable in the seventh and eighth months. Experiments during the eighth month on this cue gave, in 80 cases, right hand 74 cases, left hand 5 cases, both hands 1 case. In many cases the left hand followed slowly upon the lead of the right. Under the stimulus of bright colors, from 86 cases, 84 were right-hand cases, and 2 left-hand. Right-handedness had accordingly developed under pressure of muscular effort.

4. Up to this time the child had not learned to stand or to creep: hence the development of one hand more than the otber is not due to differences in weight between the two longitudinal halves: of the body. As she had not learned to speak or to utter articulate sounds with much distinctness, we may say also that right or left handedness may develop while the motor speech centre is not yet functioning.

Other points resulting incidentally are of interest in general psychology: i.e.,-

5. At the end of the seventh month the child's visual estimation of distance was exact enough to lead her invariably to refuse to reach for an object more than fourteen inches distant, her reaching distance being from nine to ten inches (based on tabulated experiments). Moderate stimuli she refused beyond thirteen inches. 
6. Of the five colors, blue, red, green, brown, white. blue and red were most attractive, and about equally so, as measured in terms of voluntary exertion in reaching for them.

7. The fact mentioned above under Paragraph 3 furnishes another item of evidence for the presence of efferent feelings of innervation. Why did the child prefer the right hand uniformly for effort, if not under the feeling of stronger outward nervous pressure in the case of that hand? Professor James, no doubt, can explain it with his "kinaesthetic memories,"-that sword with which he decapitates so many points of evidence in his "Principles of Psychology,"-but he does not succeed in convincing many of us, any more than Bastian did in the first place. If memories of former movements with effort give "the cue," then how do you know that there are no memories of "innervation" among them? But memories of movement without effort cannot give the "cue," for my child used both hands equally in movements without effort; and the motor force of such memories woould be neutral as regards hand-preference. How simple the explanation from the point of view of "innervation"! Memories of effortless movement are all of efferent sensations: hence either hand responds, or both. Memories of movements with effort are the same memories plus memory of an afferent feeling of effort: hence the right hand moves, perhaps followed by the left; that is, a memory of feeling of innervation in former cases is re-enforced by the same feeling now. Perhaps Professor Jaines or some other "afferentist" will explain this case. The child is now (thirteenth month) a confirmed right-hander, so to speak.

I have cited only points which have their own value,-points on which observations on one child are as valuable as on many,determinations concerning the order of development of the mental functions with the physical, not determinations merely of the time of development, which may vary. Observations on single children may also be valuable as showing that an event may happen, as opposed to theories according to which such an event may not happen, under given circumstances.

University of Toronto, Oct. 18.

J. Mark BaLdWin.

\section{Deaf-Mutes.}

Professor AleXander Graham Bell, in a recent number of Science (Sept. 5) correctly quotes me as saying, "I do not discourage the intermarriages of the deaf, as they are usually more happily mated thus than where one of the parties only is deaf. The deaf need the companionship of married life more than those who bear, and it is a gross wrong to discourage it." And he adds the following statement and inquiry: "Dr. Gillett is probably the oldest teacher in America, - not oldest in years, but oldest in service,--and he is looked up to as a guide by very many in the profession. Much good might arise from a comparison of views between Dr. Gillett and those scientific gentlemen who have given most attention to the subject of heredity. May I ask him, through the columns of Science, what would he his advice in such a case as the following? A young man (not a deaf-mute) became deaf in childhood while attending public school. He has one brother who is a deaf-mute, and another who can hear. Two others of the family (believed to be hearing) died young. The father of this young man was born deaf in one ear, and lost the hearing of the other subsequently from illness. He had a congenitally deaf brother who married a congenital deaf-mute and had four children (three of them congenital deaf-mutes). The mother of the young man was a congenital deaf mute, and she also had a ibrother born deaf. The paternal grandmother of the young man was a congenital deaf-mute, and she had a brother who was born deaf. This brother married a congenital deaf-mute, and had one son born deaf. The great-grandfather of this young man (father of his paternal grandmother) was a congenital deaf-mute; and he was, so far as known, the first deaf-mute in the family. Thus deafness has come down to this young man through four successive generations, and he now wants to marry a congenital deafmute. The young lady has seven hearing brothers and sisters, and there was no deafness in her ancestry, but she herself is believed hy her family to have been born deaf. Dr. Gillett must not think that this is a purely hypothetical case, for it is not. The parties are engaged, but the marriage has not yet been consummated, and I know that Dr. Gillett's advice would have weight with the young people. The teacher of the young lady has been consulted, and she feels the responsibility deeply. Her heart is with the young couple, and she desires their happiness, and yet her judgment is opposed to the union. Will Dr. Gillett tell us what his advice would be in such a case?"

My advice in such a case as this would be for the young people to examine themselves carefully as to what their motives are in contemplating matrimony. If they have no higher thought than the animal impulse, I would advise them by no means to enter into that sacred relation; but if they are already so united in heart that each is needful to the happiness of the other, I would advise them as soon as their circumstances are such as to enable them to maintain a family in comfort, whether the children should hear or be deaf, to follow the promptings of their higher nature, with a determination to rear their children to respectability and usefulness, which they can do in one case almost as effectually as in the other. Thus one happy union will certainly be effected; while, if prevented, not only would this be estopped, but probably two unhappy, because uncongenial, ones would ensue. If deafness were a crime, or a disgrace, or entailed suffering, I would certainly discourage it; but since it does not, I deem it wise to encourage such a marriage, if the parties most interested believe, after reflection, that their own happiness will be promoted thereby.

That there are some deaf persons sprung from deaf parents is admitted, but their number is very small. There has been much discussion of late years about the advisability of deaf-mutes marrying, lest the infirmity of deafness may descend to their offspring, and a deaf variety of the human race be formed. Until a few sparrows will make spring, this hobgoblin will never materialize. Deafness is not continued by hereditary transmission in a direct line, except in rare instances. Not two per cent of the deaf and dumb are the children of deaf parents, though it cannot be denied that a susceptibility to the infirmity inheres in certain kindreds; so that we find it true, that, while a deaf pair seldom have deaf children, they have numerous other relations-as uncles; aunts; first, second, and third cousins; nephews; and nieces -who are thus afflicted. Hence, if-some philanthropist is more concerned for the happiness of those who as yet are not, and may never be, than of those who now are and will for years continue with us, let him nut discourage the marriage of those who are deaf, but that of their kinsmen; as, these being able to hear, and having all social advantages, the deprivation will not be so serious a matter to them as to their deaf relatives. The truth of this matter is, that, after laying all maudlin sentiment aside, there is no other class of people who so greatly need the companionship of the conjugal relation as the deaf and dumb. Shut out from church privileges, as preaching of the Word, prayer-meetings, socials, receptions, lectures, concerts, parties, what remains to them of all that makes life pleasurable to us? The deprivation of their hearing has not diminished their social instincts. For companionship, family ties, and festive associations, they have as strong affinities as any one. The isolation caused by deafness, I believe, makes the marital impulse stronger in them than in others. To forbid them, as some would, matrimony, the one remaining but most helpful and enjoyable of all social and family relations, is a monstrous cruelty with very little reason. For these reasons, after many years of observation, in which I have known hundreds of instances of deaf-mute unions, and after closely studying my more than two thousand pupils, one of my highest pleasures and satisfactions is to see them judiciously and happily mated in the conjugal relation. For the foregoing reasons $I$ have long approved, and still do, of the marriage of the deaf; and $I$ believe that, as a general rule, their intermarriage is more congenial, and productive of more happiness, than the marriage of deaf with hearing persons, though I have known most beautiful and happy unions of the latter kind. " Be ye not unequally yoked together," is a Scripture injunction that bears with as much force upon the deaf as upon any others. That it would be possible in process of time to generate families who would all be deaf, I fully believe. 